\title{
Paulinia cupana (Guaraná) for the treatment of cancer related fatigue in patients undergoing radiation therapy or chemotherapy: a meta-analysis of three clinical trials
}

\author{
Auro del Giglio*, Ary Serpa, Daniel Cubero, Rachel Riechelman, Maira Paschoin \\ Oncology Department ABC Foundation School of Medicine, Rua Mariana Correia 369, São Paulo 01444-000, Brasil
}

\begin{abstract}
For cancer patients undergoing radiation therapy (RT) or systemic chemotherapy (CHT), cancer-related fatigue (CRF) is a common problem that can negatively impact their quality of life. Guarana (Paullinia cupana) is a plant native to the Amazon basin that has been used as a stimulant since pre-Columbian times. PURPOSE: To evaluate the effectiveness of guarana extract on fatigue in BC patients undergoing either CHT or RT. A total of 137 cancer patients (85\% with Breast Cancer) undergoing either CHT (101) or RT (36) were randomized to receive either a placebo or guarana. In all 3 studies, the guarana was given as an unmanipulated dry extract at a dose of $75 \mathrm{mg}$ PO QD in the first two studies or $50 \mathrm{mg}$ PO BID in the third study. Patients were crossed over to the other experimental arm, and we evaluated fatigue with the Chalder Scale in all three studies. Guarana significantly improved the The Chalder Scale Global Scores $(-0.85 ; 95 \%$ CI:-1.31 to - 0.40; $p=0.0002)$; Physical Fatigue Scores $(-0.44 ; 95 \%$ CI: -0.74 to $0.13 ; p=0.005)$ and Mental Fatigue Scores $(-0.93 ; 95 \%$ CI: -1.14 to $-0.72 ; p<0.00001)$. Guarana did not produce any CTCAE grades 3 or 4 toxicities in any of the studies. Guarana is an effective, cheap and non-toxic alternative for the treatment of fatigue in cancer patients undergoing treatment.
\end{abstract}

Keywords Paulinia cupana, radiation therapy, chemotherapy

\section{INTRODUCTION}

Fatigue is a common and very distressing symptom for cancer patients (Cheville et al., 2009; Madden et al., 2006). Cancer Related Fatigue (CRF) can be defined as an unusual, persistent, and subjective sense of tiredness related to cancer or cancer treatment that interferes with usual functioning (Madden et al., 2006). CRF can affect $70 \%$ to $80 \%$ of cancer patients depending on the type of treatment, study design, patient population, and the evaluation instrument employed (Cheville et al., 2009). CRF pathophysiology is poorly understood (Wang et al., 2008) and its pharmacologic treatment is so far unsatisfactory (Minton et al., 2008). In fact, a recent metaanalysis (Minton et al., 2008) reported that methylphenidate and erythropoietin seem to offer some benefit to fatigued cancer patients, but the thrombogenic and potential tumor stimulatory activities of Erythropoietin (Bohlius et al., 2009) and the toxicities related to methylphenidate limit their wider application to cancer patients.

Guarana (paullinia cupana) is a plant native to the Amazon basin. Roasted seed extracts have been used in medicinal beverages since pre-Columbian times as stimulants, aphrodisiacs, and tonics (Smith et al., 2007). Interestingly, guarana at doses of $75 \mathrm{mg}$ daily demonstrated favorable effects on memory and cognition in a small, randomized placebo-controlled trial (Haskel et al., 2007). We conducted 3 previous studies (da Costa. et al., 2008; da

${ }^{*}$ Correspondence: Auro del Giglio

E-mail: sandrabr@netpoint.com.br

Received June 3, 2011; Accepted November 22, 2011; Published November 30, 2011

doi: http://dx.doi.org/10.5677/tang.2011.0009

(C)2011 by Association of Humanitas Medicine
Costa et al., 2009; de Oliveira Campos MP. et al., 2011) in patients with cancer aiming at evaluating guarana's effects in CRF and we report here a metaanalysis of these 3 studies.

\section{MATERIALS AND METHODS}

We have conducted to date 3 studies to evaluate guarana's effects compared to a placebo for the treatment of Cancer Related Fatigue in patients with solid tumors undergoing either chemotherapy or radiation therapy. To our knowledge, there are no other studies addressing fatigue in this population of cancer patients treated with guarana, so this meta-analysis includes all the published studies in this subject. The first study contained 26 patients with several types of solid tumors $(16 \%$ with Breast Cancer) undergoing chemotherapy; whereas the second and third studies included only non-metastatic breast cancer patients who received adjuvant radiation therapy and chemotherapy, respectively. In all 3 studies, patients were randomized to receive either the placebo or guarana followed by a cross over to the other experimental arm. Patients were crossed over to the other experimental arm after one cycle of treatment in the first study, in the middle of radiation therapy in the second study and after 21 days of treatment followed by a 7 days washout period in the third study. Guarana was given as an unmanipulated dry extract at a dose of $75 \mathrm{mg}$ by mouth once daily in the first two studies or $50 \mathrm{mg}$ by mouth twice daily in the third study (Table1).

The guarana standardized dried extract from Paullinia cupana was acquired from Cathedral Pharmaceutical Industry (NovaPampulha, Vespasiano, Minas Gerais, Brasil).Cornstarch was used as an excipient. 


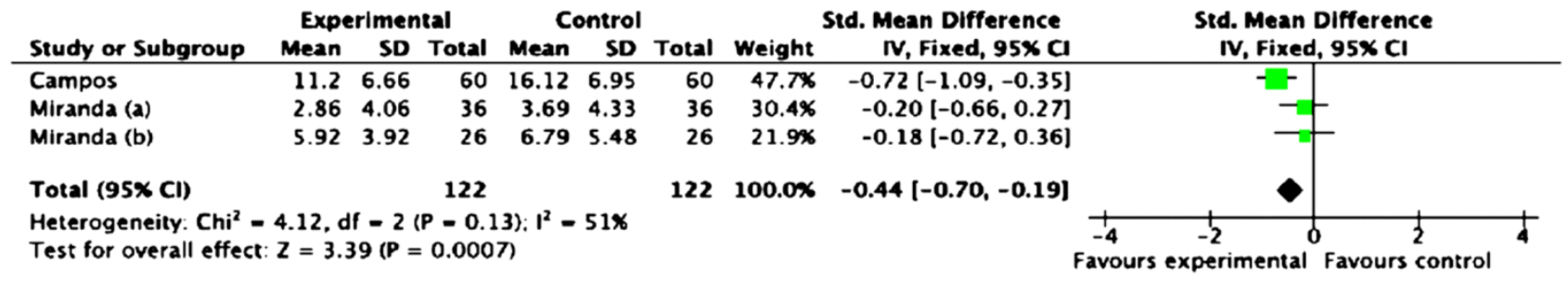

\begin{tabular}{|c|c|c|c|c|c|c|c|c|c|c|}
\hline Study or Subgroup & \multicolumn{3}{|c|}{ Experimental } & \multicolumn{3}{|c|}{ Control } & Welght & $\begin{array}{l}\text { Mean Difference } \\
\text { IV, Fixed, 95* CI }\end{array}$ & \multicolumn{2}{|l|}{$\begin{array}{l}\text { Mean Difference } \\
\text { IV. Flxed, 95\% CI }\end{array}$} \\
\hline Campos & 4.25 & 3.18 & 60 & 5.63 & 3.25 & 60 & $33.0 \%$ & $-1.38[-2.53,-0.23]$ & & \\
\hline Miranda (a) & 1.18 & 2.01 & 36 & 1.48 & 2.18 & 36 & $46.6 \%$ & $-0.30[-1.27,0.67]$ & & \\
\hline Miranda (b) & 2.19 & 2.45 & 26 & 2.53 & 2.91 & 26 & $20.4 \%$ & $-0.34[-1.80,1.12]$ & & \\
\hline Total (95\% a) & & & 122 & & & 122 & $100.0 \%$ & $-0.66[-1.33,-0.00]$ & & \\
\hline \multicolumn{9}{|c|}{$\begin{array}{l}\text { Heterogeneity: } C \mathrm{Ch}^{2}=2.22, \mathrm{df}=2(P=0.33): \mathrm{I}^{2}=10 \% \\
\text { Test for overall effect: } Z=1.97(P=0.05)\end{array}$} & erimental Favours & is control \\
\hline
\end{tabular}

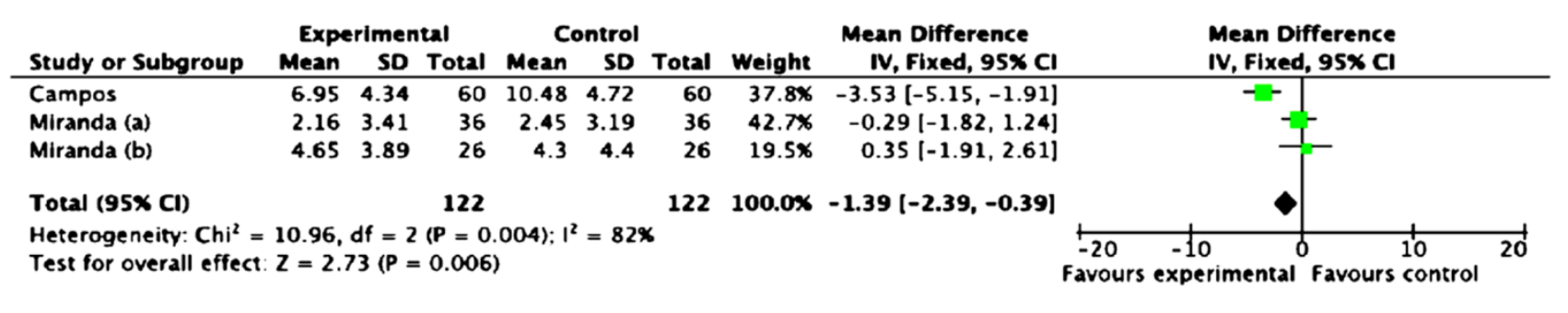

Fig. 1. Adjusted risk ratios of fatigue for patients using guarana (experimental arm) compared with placebo (control). Global scores are presented in the upper forest plot, mental scores in the middle and physical Chalder Scale scores in the lower forest plot.

All three studies employed the Chalder Scale which was already validated in Portuguese. The Chalder Fatigue Scale is a self-rated measure of fatigue severity for both physical and mental symptoms that is scored in a Likert format with response options ranging from better than usual to much worse than usual, with a total score of 26. To identify physical or mental fatigue, the patient must score at least 8 or 5 , respectively, and the presence of both high scores is considered "global fatigue" (Cho et al., 2007; Morriss et al., 1998).

The overall effects for each trial represent the aggregate of all patients treated with guarana whenever that happened (first or second phase of the study) in relation to those treated with the placebo whenever that happened (first or second phase of the study) (Elbourne et al., 2002). We computed a pooled estimate of the RRs of the individual studies using a fixed

Table 1. General characteristics of the studies

\begin{tabular}{|c|c|c|c|c|c|}
\hline Study & $\begin{array}{c}\text { Number of } \\
\text { Participants } \\
\text { (Mean Global Chalder } \\
\text { Scores at entry } \pm \text { SE) }\end{array}$ & Study Design & Oncologic Treatment/Guaraná dose & $\begin{array}{c}\text { Patient's } \\
\text { Tumour Types }\end{array}$ & Questionnaires \\
\hline
\end{tabular}

\begin{tabular}{|c|c|c|c|c|c|}
\hline $\begin{array}{l}\text { de Oliveira } \\
\text { Campos MP }\end{array}$ & $\begin{array}{c}75 \\
(11.82 \pm 0.96)\end{array}$ & Phase II RDBPCC & $\begin{array}{c}\text { Chemotherapy } \\
\text { Guarana, } 50 \mathrm{mg} / \text { twice a day } \\
\text { ( } 21 \text { days })\end{array}$ & Breast & $\begin{array}{c}\text { CFS } \\
\text { BFI } \\
\text { FACIT-F } \\
\text { FACIT-ES } \\
\text { PSQI } \\
\text { HADS } \\
\text { CTCAE }\end{array}$ \\
\hline Miranda VC & $\begin{array}{c}36 \\
(4.29 \pm 0.76)\end{array}$ & Phase II RDBPCC & $\begin{array}{c}\text { Radiotherapy } \\
\text { Guarana, } 75 \mathrm{mg} / \text { day } \\
\text { (21 days) }\end{array}$ & Breast & $\begin{array}{l}\text { CFS } \\
\text { BDI } \\
\text { BFI }\end{array}$ \\
\hline Miranda VCb & $\begin{array}{c}26 \\
(8.46 \pm 1.2)\end{array}$ & Phase II RDBPCC & $\begin{array}{c}\text { Chemotherapy } \\
\text { Guarana, } 75 \mathrm{mg} / \text { day } \\
\text { (21 days) }\end{array}$ & $\begin{array}{l}\text { Solid Tumors } \\
\text { (Breast 16\%) }\end{array}$ & $\begin{array}{l}\text { CFS } \\
\text { BDI } \\
\text { BFI }\end{array}$ \\
\hline
\end{tabular}


effect model according to Mantel and Haenszel and graphically represented these results using forest plot graphs (Fig. 1). The homogeneity assumption was checked by a $\chi^{2}$ test with a df equal to the number of analyzed studies minus 1 . We employed for all metaanalysis calculations the Review Manager software (http://www.cc-ims.net/revman).

\section{RESULTS}

These 3 studies in aggregate contained 137 patients with histologically diagnosed breast cancer undergoing either chemotherapy (26) or radiation therapy (36) in two studies not required to have baseline fatigue at entry and patients (75) with fatigue after their first cycle of chemotherapy in a third study.

Guarana significantly improved the Chalder Scale Global Scores (- 0.85 ; $95 \%$ CI: -1.31 to $-0.40 ; p=0.0002)$; Physical Fatigue Scores (- 0.44; 95\% CI: -0.74 to $-0.13 ; p=0.005)$ and Mental Fatigue Scores (- 0.93; 95\% CI: -1.14 to $-0.72 ; p<$ 0.00001 ) (Fig. 1). There was no statistically significant heterogeneity noted in all Chalder Scale Dominion scores' analysis (global, physical and mental).

Guarana did not produce any CTCAE grades 3 or 4 toxicities in any of these three studies and did not worsen sleep quality or cause anxiety or depression in the third one in which the HADS and Pittsburg Sleep Inventory Scales were employed.

\section{DISCUSSION}

Pharmacologic and non-pharmacologic treatments have all been proposed to treat CRF such as exercise, erythropoietin, methylphenidate (Minton et al., 2008), and acupuncture. However, the results of such therapies are modest at best. In fact, regarding methylphenidate, a well-conducted double-blind randomized study of methylphenidate versus a placebo produced negative results (Bruera et al., 2006). Furthermore, recent concerns voiced regarding the potential tumor stimulatory proprieties of erythropoietin (Bohlius et al., 2009) also limit the use of this drug.

This metaanalysis shows that in 137 patients, mostly with early breast cancer undergoing either radiation or chemotherapy, guarana was effective for CRF in comparison with the placebo. We were unable to identify any significant fatigue improvement with guarana (da Costa Miranda et al., 2008; da Costa Miranda et al., 2009) in the first two studies. Possible reasons are that in these two studies we included patients prior to starting radiation or chemotherapy, regardless of the presence of baseline fatigue. In fact, as can be seen in Table 1, the Chalder Global Scores at entry were higher for the patients included in the third study as compared to the first two. Furthermore, the dose of guarana used in the first two studies was lower than the one used in the third study $(75 \mathrm{mg}$ given once daily versus $50 \mathrm{mg}$ twice daily) (de Oliveira Campos MP. et al., 2011). In addition to a $33 \%$ dose increase in Guarana's dose, $50 \mathrm{mg}$ twice daily may have allowed for a more even distribution of its effects throughout the day. The small sample size of those two first studies (Table 1) also may have precluded the finding of a clinically significant effect.

Guaraná seeds contain $4-8 \%$ caffeine, as well as trace amounts of theophylline and theobromine together with large quantities of alkaloids, terpenes, tannins, flavonoids, starch, saponins, and resinous substances. The xanthine alkaloids (caffeine, theophylline, theobromine) are believed to contribute significantly to guaraná's psychostimulant activities in clinical studies (Taylor et al., 2005). Even though guarana's caffeine content is large relative to other plants such as coffee, black tea and mate, the amount of caffeine present in the dosages of 75 to $100 \mathrm{mg}$ used in the studies included in this meta-analysis may be insufficient to explain the anti-fatigue activity of this plant. It is possible that other activities of guarana yet unknown may be responsible for its anti-fatigue effects that we observed clinically in patients with cancer.

Here we showed that using a meta-analytic approach we were able to observe a significant and consistent improvement in all the Chalder Fatigue Scale dominions (global, mental and physical fatigue) with guarana when compared to a placebo when we analyzed all 3 studies in aggregate. Furthermore, no clinically significant side effects were seen in any of the 3 studies included in this meta-analysis. We thus conclude that guarana is an effective, cheap and non-toxic alternative for the treatment of fatigue in cancer patients undergoing treatment.

\section{CONFLICT OF INTEREST}

The authors do not have any conflict of interest in the present study.

\section{REFERENCES}

Bruera E, Valero V, Driver L, Shen L, Willey J, Zhang T, Palmer JL. Patient-controlled methylphenidate for cancer fatigue: a double-blind, randomized, placebo-controlled trial. J Clin Oncol. 2006;24:2073-2078.

Bohlius J, Schmidlin K, Brillant C, Schwarzer G, Trelle S, Seidenfeld J, Zwahlen M, Clarke M, Weingart O, Kluge S, Piper M, Rades D, Steensma DP, Djulbegovic B, Fey MF, RayCoquard I, Machtay M, Moebus V, Thomas G, Untch M, Schumacher M, Egger M, Engert A. Recombinant human erythropoiesis-stimulating agents and mortality in patients with cancer: a meta-analysis of randomised trials. Lancet. 2009;373:1532-1542.

Cheville AL. Cancer-related fatigue. Phys Med Rehabil Clin N Am. 2009;20:405-416.

Cho HJ, Costa E, Menezes PR, Chalder T, Bhugra D, Wessely S. Cross-cultural validation of the Chalder Fatigue Questionnaire in Brazilian primary care. J Psychosom Res. 2007;62:301-304.

da Costa Miranda V, Trufelli DC, Santos J, Campos MP, Nobuo M, da Costa Miranda M, Schlinder F, Riechelmann R, del Giglio A. Effectiveness of guarana (Paullinia cupana) for postradiation fatigue and depression: results of a pilot doubleblind randomized study. J Altern Complement Med. 2009; 15:431-433.

da Costa Miranda V, Trufelli DC, Fêde ABS, Martins FD, Saad LS, Oliveira V, Trindade TZC, Riechelman R, del Giglio A. Guarana (Paullinia cupana) for chemotherapy-related fatigue. Einstein (São Paulo). 2008;6:195-199.

de Oliveira Campos MP, Riechelmann R, Martins LC, Hassan BJ, Casa FB, Del Giglio A. Guarana (Paullinia cupana) improves fatigue in breast cancer patientsundergoing systemic chemotherapy. J Altern Complement Med. 2011;17:505-512.

Haskell CF, Kennedy DO, Wesnes KA, Milne AL, Scholey AB. A double-blind, placebo-controlled, multi-dose evaluation of 
the acute behavioural effects of guarana in humans. J Psychopharmacol. 2007;21:65-70.

Madden J, Newton S. Why am I so tired all the time? Understanding cancer-related fatigue. Clin J Oncol Nurs. 2006;10:659-661.

Minton O, Richardson A, Sharpe M, Hotopf M, Stone P. A systematic review and meta-analysis of the pharmacological treatment of cancer-related fatigue. $\mathrm{J}$ Natl Cancer Inst. 2008;100:1155-1166.

Morriss RK, Wearden AJ, Mullis R. Exploring the validity of the Chalder Fatigue scale in chronic fatigue syndrome. J Psychosom Res. 1998;45:411-417.
Smith N, Atroch AL. Guarana's Journey from Regional Tonic to Aphrodisiac and Global Energy Drink. Evid Based Complement Alternat Med. 2010;7:279-282.

Taylor L. The Healing Power of Rainforest Herbs: A Guide to Understanding and Using Herbal Medicinals. $1^{\text {st }}$ ed. (New York, USA: Square One Publishers), 2005.

Wang XS. Pathophysiology of cancer-related fatigue. Clin J Oncol Nurs. 2008;12:11-20. 